Revue

Revue de l'histoire des religions

de Ihistoire

des religions

$3 \mid 2010$

Varia

Florent QUELLIER et Georges PROVOST (sous la direction de), Du ciel à la terre : clergé et agriculture XVI ${ }^{e}$-XIX ${ }^{e}$ siècles

Rennes, Presses Universitaires de Rennes, 2008, 365 p., $25 \mathrm{~cm}$

(« Histoire »), $19 €$.

Frédéric Schwindt

OpenEdition

Journals

Édition électronique

URL : http://journals.openedition.org/rhr/7639

DOI : $10.4000 /$ rhr.7639

ISSN : 2105-2573

Éditeur

Armand Colin

Édition imprimée

Date de publication : 1 octobre 2010

Pagination : 405-407

ISBN : 978-2200-92657-1

ISSN : 0035-1423

Référence électronique

Frédéric Schwindt, «Florent aueluer et Georges provost (sous la direction de), Du ciel à la terre : clergé et agriculture $-x v I^{e}-x \mid x^{e}$ siècles », Revue de l'histoire des religions [En ligne], $3 \mid$ 2010, mis en ligne le 26 janvier 2011, consulté le 22 septembre 2020. URL : http://journals.openedition.org/rhr/7639 ; DOI : https://doi.org/10.4000/rhr.7639

Ce document a été généré automatiquement le 22 septembre 2020

Tous droits réservés 


\section{Florent QUELLIER et Georges PROVOST (sous la direction de), Du ciel à la terre : clergé et agriculture - XVI $-\mathrm{XIX}{ }^{e}$ siècles}

Rennes, Presses Universitaires de Rennes, 2008, 365 p., $25 \mathrm{~cm}$

(« Histoire »), $19 €$.

Frédéric Schwindt

\section{RÉFÉRENCE}

Florent QUELLIER et Georges PROVOST (sous la direction de), Du ciel à la terre : clergé et agriculture - XVI ${ }^{e}$-XIX ${ }^{e}$ siècles, Rennes, Presses Universitaires de Rennes, 2008, 365 p., 25 cm (« Histoire »), $19 €$.

1 C'est un joli colloque international que celui qui s'est tenu à Rennes en septembre 2006 et dont les actes sont publiés aujourd'hui. Florent Quellier et Georges Provost, tous les deux maîtres de conférences en histoire moderne à l'Université de Rennes, ont choisi de croiser leurs affinités respectives pour l'histoire économique et sociale et l'histoire religieuse du monde rural en investiguant les rapports du clergé et de l'agriculture. Sous le contrôle de deux arbitres, Jean-Marc Moriceau (directeur de la revue Histoire et sociétés rurales) et Régis Bertrand, qui rédigent aussi les conclusions de l'ouvrage, le projet du colloque consistait en effet à mettre en présence des spécialistes de ces deux disciplines afin de nourrir un dialogue qu'on espérait fructueux.

2 La chronologie est très large, du début des temps modernes jusqu'à l'époque contemporaine, et les 25 interventions s'intéressent autant aux puissances européennes, France, Espagne, Italie ou Angleterre qu'au Québec ou à la montagne libanaise. Le renouveau actuel de l'histoire rurale remet de plus en plus en cause l'idée du village immobile qui fut longtemps tenue comme un postulat. Les populations 
rurales n'étaient en effet pas aussi routinières et soumises qu'on le pensait. Déjà dans le domaine de la justice, on sait depuis les travaux d'Hervé Piant (Une justice ordinaire, PUR, 2007) que les paysans étaient capables d'instrumentaliser les tribunaux et d'utiliser les procédures à leur profit. De même, on s'aperçoit désormais que la Réforme catholique n'a pas été un mouvement frontal, Rome décidant, les missionnaires agissant et le peuple acceptant de changer ses comportements, mais un subtil échange qui a permis aux fidèles de conserver longtemps un pouvoir réel au sein des paroisses.

3 Tout aussi important est de déterminer le niveau où se noue ce dialogue permanent. Le clergé est un de ces pivots. Le domaine le plus connu était sans doute celui des jardins de curé, moyen par lequel les prêtres pouvaient directement montrer l'exemple, cet enclos devenant presque un monde à part, une sorte de projection visible des tenants et aboutissants du projet tridentin. Mais l'Église a également joué un grand rôle dans la naissance de l'agronomie, voire dans le lancement de grands projets à l'image des tentatives de bonification organisées en Espagne au xviII ${ }^{\mathrm{e}}$ siècle par le cardinal Belluga. L'intérêt pour la question est général, comme le montrent les exemples venus de Venise, d'Aquitaine ou de Normandie, et il concerne tous les cultes, les prêtres catholiques comme les pasteurs protestants d'Alsace. Surtout, l'ouvrage démontre qu'au-delà des cas exceptionnels, le pouvoir d'impulsion du clergé existe partout, même de manière non consciente, grâce aux liens nombreux que les Églises entretiennent avec l'économie rurale. Ces ponts vont d'ailleurs subsister très longtemps en Angleterre où les cathédrales ont continué à recevoir des terres. En France, de nombreuses organisations d'origine religieuse, fraternités de prêtres, confréries, fabriques étaient de fait des propriétaires terriens, mais elles surent aussi répondre à la faim d'argent des campagnes en assumant quasiment la fonction de banques rurales. Les bénéfices réalisés sur la terre étaient en effet souvent réinvestis dans le prêt à intérêt, emprunt le plus souvent caché par la subtilité du système des constitutions de rentes.

4 Même lorsque le clergé pouvait apparaître comme un frein à l'innovation, par exemple à cause des dîmes - doit-on en effet continuer de payer lorsqu'on a converti ses labours en herbages ? -, on remarque que le mouvement est clairement orienté vers le progrès et la nouveauté. Au Liban, les monastères furent ainsi en pointe dans la reconversion agricole vers la vigne qui suit la crise de la sériciculture consécutive à l'ouverture du canal de Suez. Parfois, l'innovation fut le propre d'une minorité religieuse. C'est le cas des anabaptistes-mennonites du pays de Montbéliard. Apparemment, cet exemple est hors sujet, puisqu'il n'y a en principe pas de clergé chez ces cousins directs des Amishs. En réalité, la réussite ne concerne pas toute la communauté, mais une sorte "d'aristocratie » interne qui concentre à la fois une forte capacité d'innovation, la possibilité de mobiliser rapidement des capitaux et un rôle quasi héréditaire en matière religieuse: la fonction d'ancien. La réussite des anabaptistes (qui sélectionnèrent par exemple la race montbéliarde) s'explique par un état d'esprit particulier, qui correspond assez bien aux thèses de Max Weber (L'Éthique protestante et l'esprit du capitalisme, Plon, 1964), mais aussi par la possibilité offerte à quelques familles d'utiliser de manière efficace et à leur avantage le fonctionnement communautaire en articulant économie et religion. Entre la Révolution française et la loi de séparation de l'Église et de l'État, l'intérêt des prêtres français et même de certaines congrégations monastiques pour les questions agricoles ne s'est pas démenti, même si certaines régions (Bretagne ou Franche-Comté) semblent particulièrement dynamiques. L'enseignement agricole prend racine dans l'Ouest alors que la Franche- 
Comté donne l'exemple dans la création des premières caisses d'épargne en milieu rural. Au même moment, tandis que des missionnaires agricoles se mettaient en place au Canada, le séminaire de Québec organisait un concours annuel pour ses fermiers. On peut donc conclure avec Jean-Marc Moriceau que les différents clergés ont tout autant été les promoteurs du progrès agricole que du salut. 